\title{
EFEITO RESIDUAL DE IMAZAPIC SOBRE A GERMINAÇÃO E O DESENVOLVIMENTO INICIAL DE SOJA E MILHO EM ÁREA DE RENOVAÇÃO DE CANAVIAL
}

\author{
SANTOS, Guilherme Xavier Lucio dos ${ }^{1}$; SOARES, Maria Beatriz Bernardo ${ }^{2}$; MARTINS, \\ Monica Helena ${ }^{1}$; POLLI, Katia Cristina ${ }^{3}$; CORREIA, Alessandra Neves ${ }^{1}$;FINOTO, Everton Luis ${ }^{4}$
}

ISSUE DOI: $10.3738 / 1982.2278 .3630$

\begin{abstract}
RESUMO: A sucessão e rotação de culturas são componentes vitais da agricultura moderna, porém a utilização de herbicidas com efeito residual pode acabar prejudicando uma cultura não-tolerante cultivada em sucessão. Objetivouse com este trabalho avaliar o efeito residual e a fitoxicidade do Imazapic, aplicado em diferentes épocas no solo, sobre a germinação e o desenvolvimento inicial nas culturas de soja e milho plantada em sucessão a cana. $\mathrm{O}$ ensaio foi realizado em condições de casa de vegetação na Apta Centro Norte, em Pindorama-SP. O delineamento estatístico tanto para o milho quanto para a soja consistiu-se em blocos casualizados, com 4 épocas de aplicação do imazapic (controle sem herbicida,90,60,30 e 0 dias antes do plantio do milho) e (90, 60, 30 e 0 dias antes do plantio da soja) na dose de 140 g.ha ${ }^{1}$ do produto comercial, equivalente a 98 g.ha ${ }^{1}$ do ingrediente ativo do herbicida com 5 repetições e 4 épocas distintas. Foram avaliadas as variáveis germinação, mortalidade das plantas, altura das plantas e massa seca da parte aérea. A germinação e a mortalidade de plantas foram afetadas pela aplicação do herbicida no mesmo dia do plantio. As plantas de milho foram afetadas em relação a sua altura e massa seca a partir quando o plantio ocorreu até 60 dias após a aplicação do imazapic no solo. Para o plantio da cultura imediatamente após a aplicação do imazapic constatou-se mortalidade de plantas e grave inibição de seu crescimento. O mesmo ocorreu com as plantas de soja, afetando a altura das plantas e a produção de massa seca pela parte aérea.
\end{abstract}

Palavras Chave: Glycine Max (L.) Merrill. Zea Mays. Produtividade de Grãos. Rotação de culturas.

\section{IMAZAPIC RESIDUAL EFFECT ON THE GERMINATION AND INITIAL DEVELOPMENT OF SOY AND CORN IN CANAVIAL RENEWAL AREA}

\begin{abstract}
SUMMARY: Seedling and crop rotation are vital components of modern agriculture, but the use of residual herbicides may end up harming a non-tolerant crop grown in succession. The objective of this work was to evaluate the residual effect and phytoxicity of Imazapic, applied at different times in the soil, on germination and initial development in soybean and corn crops planted in succession to sugarcane. The experiment was carried out under greenhouse conditions at the Apta Centro Norte, in Pindorama-SP. Statistical design for both maize and soybean consisted of randomized blocks, with 4 periods of application of imazapic (control without herbicide, 90,60,30 and 0 days before maize planting) and (90, 60, 30 and 0 days before planting the soybean) at the dose of $140 \mathrm{~g} \cdot \mathrm{ha}^{1}$ of the $^{2}$ commercial product, equivalent to $98 \mathrm{~g}^{\mathrm{g}} \mathrm{ha}^{1}$ of the active ingredient of the herbicide with 5 replicates and 4 distinct epochs. The variables germination, plant mortality, plant height and shoot dry mass were evaluated. Germination and plant mortality were affected by application of the herbicide on the same day of planting. The corn plants were affected in relation to their height and dry mass from when the planting occurred up to 60 days after the application of imazapic in the soil. For planting of the crop immediately after the application of imazapic, plant mortality and severe inhibition of its growth were observed. The same happened with the soybean plants, affecting the height of the plants and the production of dry mass by the aerial part.
\end{abstract}

Keywords: Glycine Max (L.) Merrill. Zea Mays. Grain Productivity. Rotation of crops.

\footnotetext{
${ }^{1}$ Eng. Agrônomo, Bolsista de Aperfeiçoamento Técnico, FUNDAG/ Agência Paulista de Tecnologia dos Agronegócios-APTA/Secretaria de Agricultura e Abastecimento-SAA - Polo Regional Centro Norte Pindorama,SP;

${ }^{2}$ Eng. Agrônomo, Msc., Pesquisador Cientifico na APTA/SAA - Polo Regional Centro Norte - Pindorama;

${ }^{3}$ Graduando em Agronomia, Centro Universitário de Rio Preto-UNIRP, Bolsista PIBIC/CNPq/APTA/SAA - Polo Regional Centro Norte - Pindorama;

${ }^{4}$ Eng. Agrônomo, Dr., Pesquisador Cientifico, APTA/SAA, Polo Regional Centro Norte - Pindorama;
} 


\section{INTRODUÇÃO}

As culturas do milho (Zea mays L.) e da soja (Glycine max (L.) Merril) destacam-se como graníferas de grande importância na alimentação humana e animal. No Brasil, a área cultivada com milho e soja na safra 2017/18 representou 85\% da área total de grãos semeada (BRASIL, 2018). Por serem espécies de ciclo curto (90-150 dias), essas culturas são frequentemente cultivadas em sucessão/rotação entre elas e com outras, estando portanto sujeitas a efeitos positivos, como a interrupção de ciclos de vida de pragas e de doenças e a melhoria da qualidade do solo, e negativos, como o efeito residual de herbicidas no solo de práticas utilizadas no cultivo anterior.

Diversos herbicidas que apresentam longa atividade residual no solo vêm sendo utilizados em larga escala no Brasil. Esses compostos, dependendo de sua estrutura química e das condições edafológicas e climáticas, podem não ser completamente degradados durante o ciclo da cultura principal, deixando resíduos indesejáveis no solo, os quais podem afetar a cultura subsequente e comprometer o ambiente (SILVA et al., 1999).

Destacam-se o grupo químico das triazinas, é um herbicida registrado e amplamente utilizado na cultura do milho, classificado como de moderada persistência no solo e muito perigoso ao meio ambiente pela alta lixiviabilidade (ARCHANGELO et al., 2005)., e o das imidazolinonas, para as culturas da soja (BRIGHENTI et al., 2002). O risco de intoxicação às culturas devido à presença de resíduos de herbicidas de longa persistência desses grupos deve ser considerado.

O imazapic é considerado seletivo para a cultura do amendoim e da cana-de-açucar, não sendo tóxico as culturas (RICHHBURG et al, 1995), controlando plantas daninhas, principalmente a tiririca (Cyperus rotundus). Porém sabe-se que herbicidas deste grupo (imidazolinonas), podem persistir no solo de 31 a 410 dias e afetar culturas não-tolerantes cultivadas em sucessão (GRYMES, 1995). Sua persistência, aplicada isoladamente ou em mistura em diferentes solos e regiões climáticas, tem sido investigada, com efeitos fitotóxicos sobre culturas sensíveis como arroz, feijão, soja, girassol, algodão, pepino e cenoura cultivadas em sucessão na área (CARVALHO et al., 2010; FURLAN et al., 2016). Assim, considerar o período residual do herbicida é importante para definir o sucesso da cultura em sucessão.

Segundo Soares et al. (2011) a reforma dos canaviais é importante para manter elevada a média de produtividade agrícola de uma usina. A decisão pela rotação divide-se entre a autoprodução e a terceirização, que dependerão dos recursos internos e do conhecimento da usina sobre a nova cultura. (OLIVEIRA; PEREIRA; VIEIRA, 2012)

Segundo Zhang et al. (2002), a sucessão e rotação de cultivos são componentes vitais da agricultura moderna. A adoção dessas práticas por parte dos agricultores é considerada decisão inteligente, uma vez que a monocultura pode promover um declínio na produtividade da maioria dos cultivos.

Objetivou-se com este trabalho avaliar o efeito residual e a fitotoxicidade do imazapic, aplicado em diferentes épocas em solo retirado de área de renovação de cana-de-açucar, sobre a germinação e o desenvolvimento inicial das culturas da soja e do milho.

\section{MATERIAL E MÉTODO}

O experimento foi realizado em casa de vegetação no Pólo Regional Centro Norte, pertencente á Agencia Paulista de Tecnologia dos Agronegócios (APTA), no município de Pindorama-SP. Utilizou-se o delineamento em blocos ao acaso com 5 tratamentos (épocas de aplicação do imazapic) e 5 repetições. Os tratamentos foram: solo sem a aplicação do herbicida (testemunha), solo com herbicida aplicado 90, 60, 30 e 0 dias antes do plantio das culturas de rotação. 
Cada parcela experimental constituiu-se de 5 vasos de 5 litros, nos quais foram plantadas 4 sementes da cultura de sucessão cada. Para o milho foram utilizadas sementes do híbrido DKB 390 e para a soja foram utilizadas sementes da cultivar M 7908RR. Os vasos foram preenchidos com solo de textura média, nos quais foi aplicada, em 4 épocas distintas, a dose de $140 \mathrm{~g}$ ha- $^{1}$ do produto comercial, equivalente a $98 \mathrm{~g}$ ha- $^{-1}$ do ingrediente ativo do herbicida.

A aplicação dos tratamentos foi feita sobre o solo sem cobertura vegetal utilizando-se pulverizador costal pressurizado por $\mathrm{CO}_{2}$ munido de barras com quatro bicos com pontas tipo leque (TTJ60-11002 VP) espaçados de $0,5 \mathrm{~m}$ entre eles, operando a $4 \mathrm{kgf} / \mathrm{cm} 2$ de pressão e trabalhando com volume de calda correspondente a $300 \mathrm{Lha}^{-1}$.

Os solos pulverizados com o herbicida Os solos pulverizados com o herbicida foram mantidos em ambiente desprotegido, expostos às intempéries e sob as condições normais de campo. Após o plantio das sementes de milho e de soja, essas foram irrigadas manualmente objetivando-se manter o solo a $80 \%$ da capacidade de campo. Aos 7 dias após o plantio foi efetuada a contagem de plantas germinadas.. Aos 30 dias após o plantio contou-se o stand final para avaliar a mortalidade e mediu-se a altura da parte aérea com auxilio de régua milimetrada.

Após a medição da altura das plantas, a parte aérea foi retirada e seca em estufa de circulação de ar forçada a $65^{\circ} \mathrm{C}$ até atingir massa constante. A matéria seca da parte aérea foi obtida utilizando-se balança de precisão.

Os dados referentes à germinação e à mortalidade das plantas foram transformados em $\operatorname{arcosen}[(\mathrm{x}+0,5) / 100]^{-1 / 2} \mathrm{e}$ os dados referentesà altura de plantas e massa seca da parte aérea não sofreram transformações. As médias dos tratamentos foram comparadas pelo teste de Tukey a 5\% de probabilidade de erro. Os dados quantitativos foram submetidos ao teste de regressão.

\section{RESULTADO E DISCUSSÃO}

As plantas de soja, ao longo de seu desenvolvimento, apresentaram sintomas de fitotoxicidade para os tratamentos com intervalos entre a aplicação do herbicida e plantio das sementes menores ou igual a 60 dias, como manchas cloróticas nas folhas, necroses, enrolamento dos ápices foliares e inibição do crescimento.

A persistência de herbicidas do grupo químico das imidazolinonas, ao qual pertence o imazapic, é influenciada por propriedades do solo, como o pH, a umidade, o teor de matéria orgânica e a textura (STOUGAARD et al., 1990).

Na Tabela 1 pode-se observar que, apesar da germinação e da mortalidade das plantas aos 30 dias após o plantio não diferirem significativamente entre si e da testemunha, a aplicação do herbicida afetou a altura e a massa seca das plantas aos 30 dias após o plantio, sendo esta cultivar sensível à aplicações com intervalos menores que 60 dias do plantio. Segundo Monqueiro et al. (2010) a maior atividade residual do imazapic se dá até os 45dias após sua aplicação, entretanto ainda aos 210 dias após a aplicação este ainda apresenta alguma atividade residual.

Apesar de a soja mostrar-se tolerante a alguns herbicidas do grupo das imidazolinonas, o imazapic isolado não é um herbicida recomendado para a cultura. Estudos conduzidos por Agostinetto et al (2018) mostram a suscetibilidade da cultivar NA5909RR (com tecnologia Roundup Ready®) aos resíduos da mistura formulada de imidazolinonas (imazapyr + imazapic) aplicada no arroz no sistema Clearfield®. 
Tabela1. Avaliação dos fatores germinação (\%), mortalidade $(\%)$, altura da parte aérea $(\mathrm{cm})$ e massa da parte aérea (g) de plantas de soja em diferentes épocas de aplicação de imazapic antes do plantio. Pindorama, 2010

\begin{tabular}{ccccc}
\hline Época de Aplicação & $\begin{array}{c}\text { Germinação } \\
(\mathbf{\%})\end{array}$ & $\begin{array}{c}\text { Mortalidade } \\
(\mathbf{\%})\end{array}$ & $\begin{array}{c}\text { Altura } \\
(\mathbf{c m})\end{array}$ & $\begin{array}{c}\text { Massa } \\
\text { Seca } \\
(\mathbf{g})\end{array}$ \\
\hline 90 dias antes do plantio & 94,00 & 1,00 & $18,44 \mathrm{AB}$ & $7,35 \mathrm{~A}^{1}$ \\
60 dias antes do plantio & 90,00 & 2,50 & $18,30 \mathrm{AB}$ & $7,07 \mathrm{~A}$ \\
30 dias antes do plantio & 85,00 & 4,00 & $17,02 \mathrm{~B}$ & $6,74 \mathrm{AB}$ \\
0 dias antes do plantio & 86,00 & 8,00 & $14,12 \mathrm{C}$ & $5,37 \mathrm{~B}$ \\
Testemunha & 95,00 & 2,00 & $19,50 \mathrm{~A}$ & $7,45 \mathrm{~A}$ \\
\hline F & $1,72^{\mathbf{n s}}$ & $1,14^{\mathrm{ns}}$ & $19,78^{* *}$ & $6,65^{* *}$ \\
CV $(\%)$ & 11,15 & 35,08 & 5,97 & 10,74 \\
DMS & 15,9811 & 13,5486 & 2,0213 & 1,4134 \\
\hline
\end{tabular}

1 Médias seguidas pela mesma letra na coluna não diferem entre si pelo teste de Tukey a $5 \%$ de probabilidade. ${ }^{\text {ns }}$ Não significativo. $* *$ Significativo a $1 \%$ de probabilidade.

Não houve modificação. Apesar da redução significativa da germinação.

Se desconsiderada para comparação a testemunha sem a aplicação, nota-se que há uma tendência significativa da germinação (Figura 1), altura das plantas (Figura 3) e massa seca das plantas (Figura 4) aumentarem e a mortalidade das plantas aos 30 dias após o plantio (Figura 2) diminuir, à medida que se aumenta o período entre a aplicação do imazapic e o plantio da soja em sucessão.

Figura 1. Germinação (\%) da soja plantadas aos 0, 30, 60 e 90 dias após a aplicação de imazapic no solo

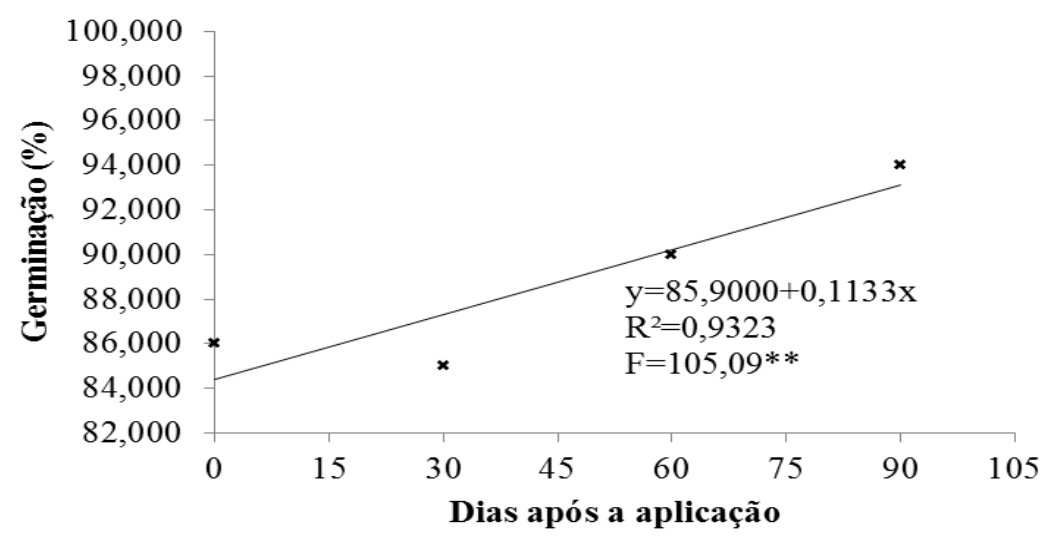

Figura 2. Mortalidade (\%) das plantas de soja plantadas aos 0,30,60 e 90 dias após a aplicação de imazapic no solo.

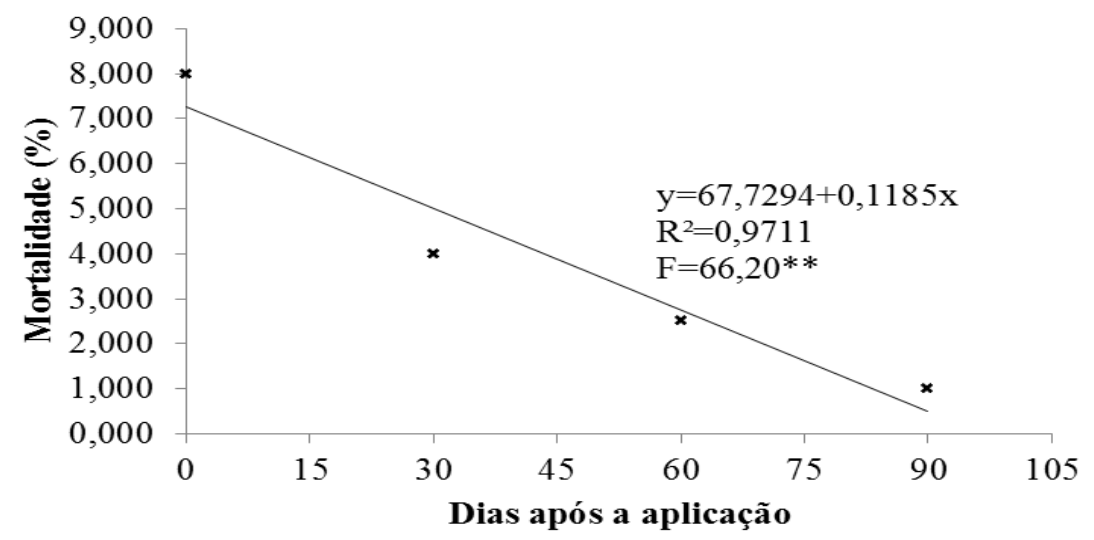


Figura 3. Altura $(\mathrm{cm})$ das plantas de soja plantadas aos 0, 30, 60 e 90 dias após a aplicação de imazapic no solo.

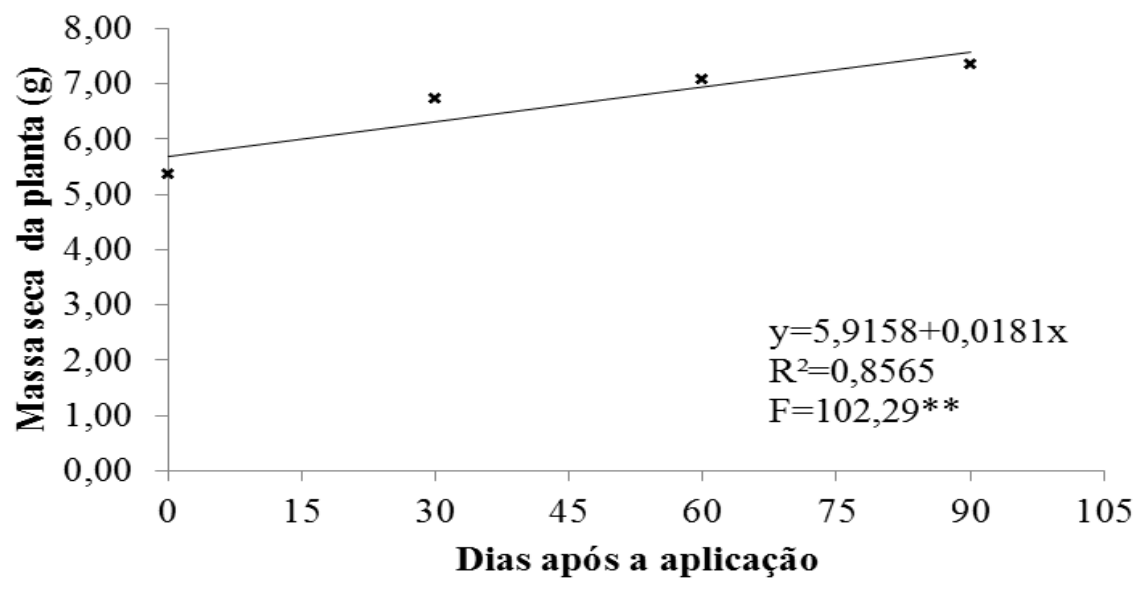

Figura 4. Massa seca (g) das plantas de soja plantadas aos 0, 30, 60 e 90 dias após a aplicação de imazapic no solo.

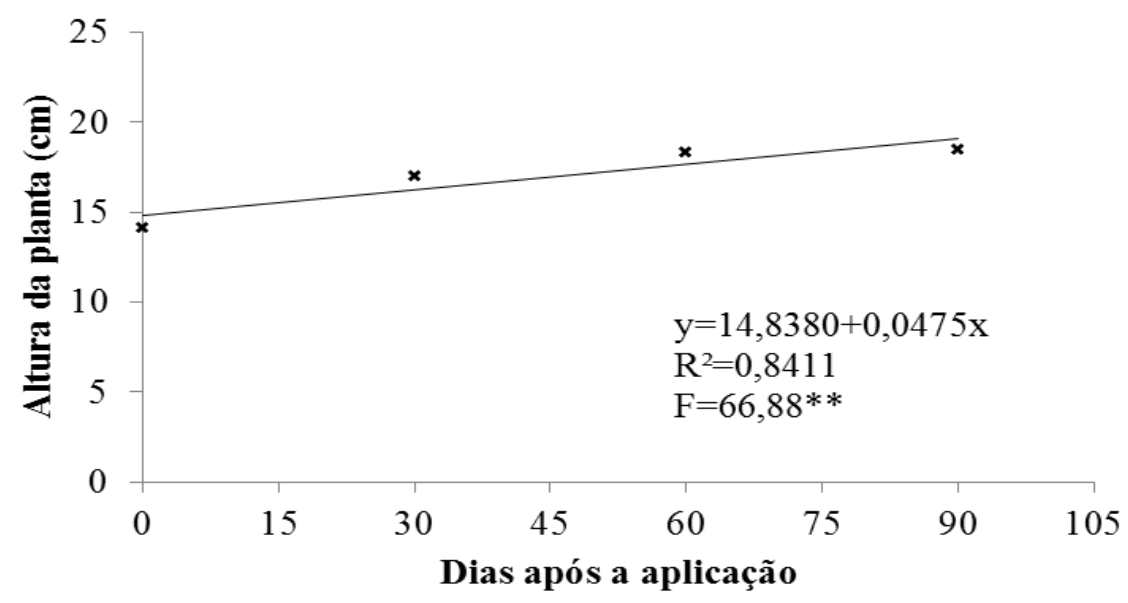

A altura das plantas foi negativamente afetada nos plantios em prazos menores a 60 dias da última aplicação de imazapic, sendo severamente diminuída no tratamento em que a cultura foi plantada no mesmo dia da aplicação do imazapic. Porém cabe ressaltar que mesmo aos 90 dias da última aplicação de imazapic, este exerce efeito residual intermediário sobre a altura das plantas de soja. Em relação à massa seca da parte aérea das plantas, os tratamentos com aplicação do herbicida 30 dias antes do plantio da soja proporcionou diminuição mediana da massa seca das plantas em relação à testemunha. No caso do intervalo de 90 e 60 dias entre a aplicação e o plantio da cultura, houve ligeira diminuição da massa seca da parte aérea, porém não significativa. $O$ tratamento do solo no mesmo dia do plantio afetou significativamente essa variável. Os resultados mostram que, assim como na altura da planta, a atividade residual no solo de imazapic também pode ser observada através do acúmulo de massa seca. Esses resultados estão de acordo com os estudos realizado por Alister et al. (2005), nos quais 9 culturas tiveram sua massa seca reduzida mesmo 300 dias após a aplicação de (imazapyr + imazapic) ou (imazapyr + imazethapyr).

Observa-se com que o desenvolvimento inicial da soja é sensível ao efeito residual do imazapic aplicado em sua cultura antecessora, sobretudo se a aplicação do herbicida se der a menos de 30 dias do 
plantio da cultura da soja, afetando a altura das plantas e a produção de massa seca pela parte aérea. Ainda que a soja seja sensível ao imazapic, Ulbrich et al. (2005), avaliando o resíduo de imazapir+imazapique no desenvolvimento inicial de diferentes espécies, constataram que a soja apresentou menor sensibilidade entre culturas como feijão, trigo e milho.

As plantas de milho, ao longo de seu desenvolvimento, apresentaram sintomas de fitotoxicidade para alguns dos tratamentos, como manchas cloróticas nas folhas, necroses, enrolamento dos ápices foliares e inibição do crescimento.

$\mathrm{Na}$ Tabela 2 é possível observar que a germinação das sementes de milho difere significativamente apenas quando o herbicida é aplicado no dia do plantio sendo drasticamente afetada.

Tabela2. Avaliação dos fatores germinação (\%), mortalidade $(\%)$, altura da parte aérea $(\mathrm{cm})$ e massa da parte aérea $(\mathrm{g})$ de plantas de milho em diferentes épocas de aplicação de imazapic antes do plantio. Pindorama, 2010

\begin{tabular}{ccccc}
\hline $\begin{array}{c}\text { Época de Aplicação do } \\
\text { Imazapic }\end{array}$ & $\begin{array}{c}\text { Germinação } \\
(\mathbf{\%})\end{array}$ & $\begin{array}{c}\text { Mortalidade } \\
(\mathbf{\%})\end{array}$ & $\begin{array}{c}\text { Altura } \\
(\mathbf{c m})\end{array}$ & Massa Seca (g) \\
\hline Controle & $99,00 \mathrm{a} 1$ & $1,00 \mathrm{~b}$ & $30,55 \mathrm{a}$ & $8,90 \mathrm{a}$ \\
90 dias antes do plantio & $95,00 \mathrm{a}$ & $5,46 \mathrm{~b}$ & $32,04 \mathrm{a}$ & $8,13 \mathrm{ab}$ \\
60 dias antes do plantio & $93,00 \mathrm{a}$ & $3,38 \mathrm{~b}$ & $22,84 \mathrm{~b}$ & $6,16 \mathrm{bc}$ \\
30 dias antes do plantio & $94,00 \mathrm{a}$ & $6,40 \mathrm{~b}$ & $22,72 \mathrm{~b}$ & $5,35 \mathrm{c}$ \\
0 dias antes do plantio & $67,00 \mathrm{~b}$ & $38,36 \mathrm{a}$ & $12,23 \mathrm{c}$ & $1,66 \mathrm{~d}$ \\
\hline F & $21,8278^{* *}$ & $15,2825^{* *}$ & $64,5997^{* *}$ & $25,8354^{* *}$ \\
CV(\%) & 8,85 & 54,43 & 9,12 & 20,65 \\
DMS & 11,92513 & 14,81635 & 4,26048 & 2,4214 \\
\hline
\end{tabular}

${ }^{1}$ Médias seguidas de mesma letra minúscula na linha e maiúscula na coluna não diferem significativamente entre si pelo teste de Tukey a 5\% de probabilidade de erro. ** Teste $\mathrm{F}$ significativo a $1 \%$ de probabilidade de erro.

A mortalidade das plantas ao longo dos 30 dias variou significativamente entre os tratamentos sendo o plantio da cultura do milho imediatamente após a aplicação do herbicida aumentou significativamente a mortalidade das plantas de milho. Resultados similares foram encontrados por Villa et al.(2006) em plantio de arroz não-tolerante a imidazolinonas no qual houve uma perda no estande aos 19 dias após a emergência, indicando a morte de plântulas, mesmo após 361 dias da aplicação do herbicida.

Apesar da mortalidade das plantas de milho ter sido pouco afetada, parâmetros biométricos como altura da planta e massa seca da parte aérea, os quais estão relacionados diretamente com a produtividade da cultura foram bastante afetados.

A altura das plantas foi negativamente afetada nos plantios em prazos menores a 60 dias da última aplicação de imazapic, sendo severamente diminuída no tratamento em que a cultura foi plantada no mesmo dia da aplicação do imazapic. Porém cabe ressaltar que aos noventa dias da última aplicação de imazapic, este já não exerce efeito residual significativo sobre a altura das plantas de milho. O efeito residual negativo de herbicidas do grupo químico da imadazolinonas sobre a altura das plantas de culturas em sucessão também foi observado em plantas de azevém por Pinto et al. (2009) e em milho por Gazziero et al. (1997).

Em relação à massa seca da parte aérea das plantas, os tratamentos com aplicação do herbicida proporcionaram diminuição em relação a testemunha. No caso do intervalo de 90 dias entre a aplicação e o plantio da cultura, houve ligeira diminuição da massa seca da parte aérea não chegando a ser significativa. Entretanto os demais tratamentos afetaram mais significativamente essa variável. Os resultados mostram que, assim como na altura da planta, a atividade residual no solo de imazapic também pode ser observada através do acúmulo de massa seca. Esses resultados estão de acordo com os encontrados por Pinto et al. 
(2009) para azevém , Silva et al. (1999) para sorgo semeado 60 dias após a aplicação do herbicida imazethapyr, pertencente ao mesmo grupo químico do imazapic.

Assim como ocorreu para a soja plantada em sucessão, se desconsiderada testemunha sem a aplicação do herbicida, nota-se que há uma tendência significativa da germinação (Figura 5), altura das plantas (Figura 7) e massa seca das plantas (Figura 8) aumentarem e a mortalidade das plantas aos 30 dias após o plantio (Figura 6) diminuir, à medida que se aumenta o período entre a aplicação do imazapic e o plantio do milho em sucessão.

Figura 5. Germinação (\%) das plantas de milho plantadas aos 0, 30, 60 e 90 dias após a aplicação de imazapic no solo.

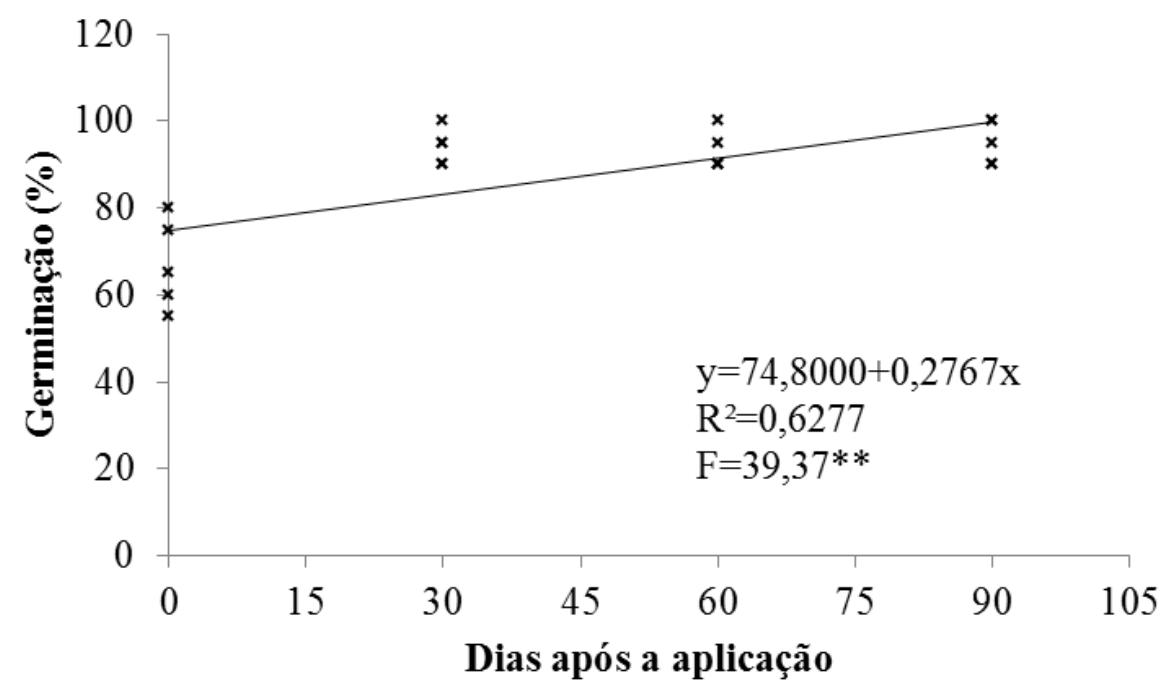

Figura 6. Mortalidade (\%) das plantas de milho plantadas aos 0, 30, 60 e 90 dias após a aplicação de imazapic no solo.

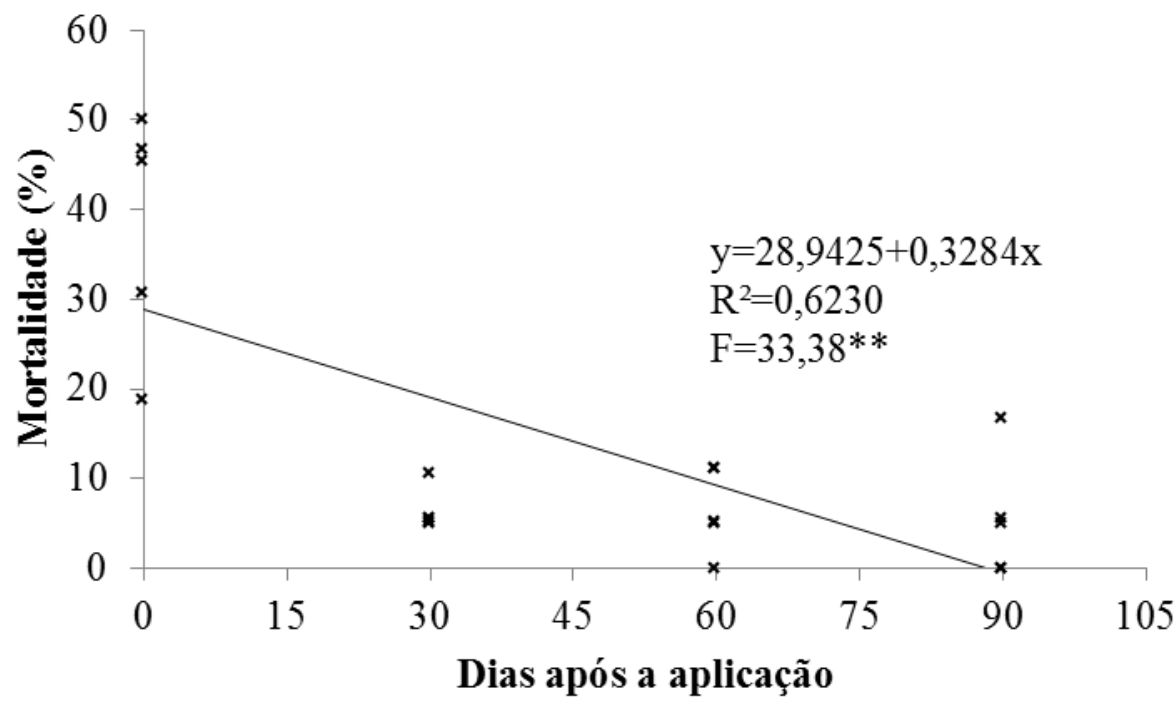


Figura 7. Altura $(\mathrm{cm})$ das plantas de milho plantadas aos 0, 30, 60 e 90 dias após a aplicação de imazapic no solo

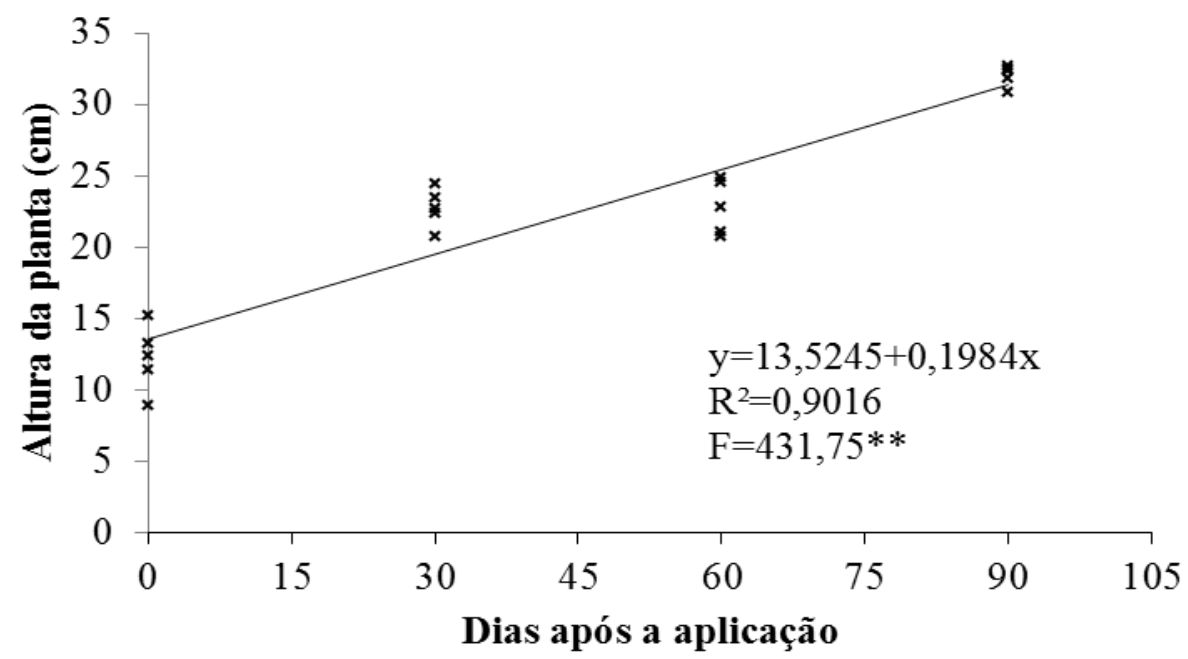

Figura 8. Altura $(\mathrm{cm})$ das plantas de milho plantadas aos 0, 30, 60 e 90 dias após a aplicação de imazapic no solo

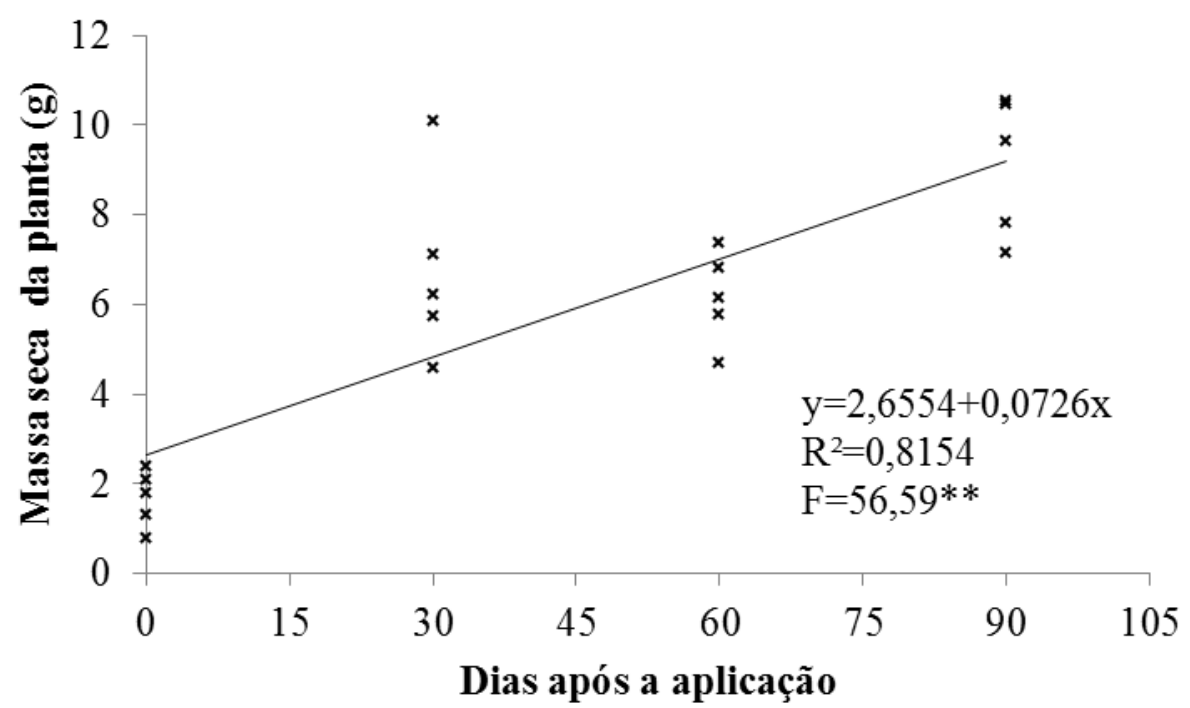

Quando consideradas as áreas de reforma do canavial, em que a aplicação do imazapic em pósemergência normalmente ocorre na época chuvosa antes do fechamento das entrelinhas pela cultura, o período entre a aplicação do imazapic e o plantio da cultura em sucessão costuma ser superior a 180 dias, ou seja, não deve causar problemas no estabelecimento e desenvolvimento das culturas de soja e milho em sucessão.

\section{CONCLUSÃO}

A aplicação do imazapic imediatamente antes do plantio das culturas de milho e soja ou até 30 dias antes do plantio, afeta severamente o estabelecimento e desenvolvimento das culturas do milho e da 
soja plantadas em sucessão, causando falhas na germinação, amentando a mortalidade e diminuição da altura e biomassa das plantas.

O plantio de soja ou milho 60 dias após a aplicação do imazapic não causa problemas no estabelecimento e desenvolvimento inicial destas culturas.

\section{REFERÊNCIAS}

AGOSTINETTO, D.et al. Response of Soybean Cultivars in Rotation with Irrigated Rice CropsCultivated in Clearfield® System. Planta daninha, Viçosa, v. 36, e 018170991, 2018. Available from<http://www.scielo.br/scielo.php?script=sci_arttext\&pid=S010083582018000100250\&lng=en\&nrm= iso>. access on 27 May 2019. Epub July 10, 2018. http://dx.doi.org/10.1590/s010083582018360100048

ALISTER, C.; KOGAN, M. Efficacy of imidazolinone herbicides applied to imidazolinone resistant maize and their carryover effect on rotational crops. Crop Protection, v. 24, n. 4, p. 375- 379, 2005.

ARCHANGELO, E. R.et al. Sorção, dessorção e potencial de lixiviação de Atrazine em solos brasileiros. Revista Brasileira de Milho e Sorgo, v. 4, n. 1, p. 14-27, 2005. doi: 10.18512/1980-6477/ rbms.v4n1p1427.

BRASIL. Ministério da Agricultura, Pecuária e Abastecimento. Agrofit: sistema de agrotóxicos fitossanitário. Ministério da Agricultura, Pecuária e Abastecimento, Brasília, DF, 2018. Disponível em: . Acesso em: 20 fev. 2018.

BRIGHENTI, A. M.; MORAES, V.J.; OLIVEIRA, J.R. Persistência e fitotoxicidade do herbicida atrazine aplicado na cultura do milho sobre a cultura do girassol em sucessão. Planta Daninha, v. 20, n. 2, p. 291297, 2002.

CARVALHO, F. T.; MORETTI, T. B.; SOUZA, P. A. Efeito do residual no solo de nicosulfuron isolado e em mistura com Atrazine sobre culturas agrícolas subsequentes. Revista Brasileira de Herbicidas, v. 9, n. 1, p. 26-34, 2010. doi: 10.7824/rbh.v9i1.76.

FURLAN, R. G.et al. Simulação do efeito residual da Atrazine em cenoura. Horticultura Brasileira, v. 34, n. 4, p. 584-587, 2016. doi: 10.1590/ s0102-053620160420.

GRYMES, C.F. Response of soybean (Glycine max) and rice (Oryza sativa) in rotation to AC 263222.Weed Tecnology, v.9, p.504-511, 1995.

GAZZIERO, D. L. P.et al. Persistência dos herbicidas imazaquin e imazethapyr no solo e os efeitos sobre plantas de milho e pepino. Planta Daninha, v. 15, n. 2, p. 162-169, 1997.

MONQUERO, P.A. et al. Lixiviação e persistência dos herbicidas sulfentrazone e imazapic. Planta daninha, Viçosa, v. 28, n. 1, p. 185-195, 2010.

OLIVEIRA, AF; O PEREIRA, CN; VIEIRA, PA. Análise da rotação de grãos na área de reforma de canavial. Congresso da Sociedade de Brasileira de Economia, Administração e Sociologia Rural, 50, 2012, Vitória. Anais...Vitória: Sociedade Brasileira de Economia, Administração e Sociologia Rural: UFES, 2012.

PINTO, J.J.O.et al. Atividade residual de (imazethapyr+imazapic) sobre azevém anual (Lolium multiflorum), semeado em sucessão ao arroz irrigado, sistema clearfield®. Planta Daninha, Viçosa, v. 27, n. 3, 2009 . 
SILVA, A. A.et al. Efeito residual no solo dos herbicidas imazamox e imazethapyr para as culturas de milho e sorgo. Planta Daninha, v. 17, n. 3, p. 345-354, 1999.

SOARES, M. B. B.et al.Fitossociologia de plantas daninhas sob diferentes sistemas de manejo de solo em áreas de reforma de cana crua. Revista Agro@mbiente On-line, Boa Vista, v. 3, n. 5, p. 173-181, 2011.

RICHHBURG, J. S.; WILCUT, J. W.; WILLEY, G. L. AC 263,222 and imazethapyr rates and mixture for weed management in peanut (Arachis hypogaea). Weed Technology, v. 9, p. 801-806, 1995.

STOUGAARD, R. N.; SHEA, P. J.; MARTIN, A. R. Effect of soil type and pH on adsorption, mobility, and efficacy of imazaquin and imazethapyr. Weed Science, v. 38, p. 67-73, 1990.

VILLA, S.C.C.et al Arroz tolerante a imidazolinonas: controle do arroz-vermelho, fluxo gênico e efeito residual do herbicida em culturas sucessoras não-tolerantes. Planta Daninha, Viçosa, v. 24, n. 4, Dec. 2006.

ZHANG, W.; WEBSTER, E. P.; BRAVERMAN, M. P. Rice (Oryza sativa) response to rotational crop and rice herbicide combinations. Weed Technology., v. 16, p. 340-345, 2002 